PLANNING TO CARE: THE CASE FOR A BROADER IMPLEMENTATION OF THERAPEUTIC PLANNING

\author{
by \\ David Matthew Alton \\ BAH, University of Guelph, 2014 \\ A Major Research Paper \\ Presented to Ryerson University \\ In partial fulfillment of the requirements for the degree of \\ Master of Planning \\ in \\ Urban Development
}

Toronto, Ontario, Canada, 2018 


\section{Author's Declaration for Electronic Submission of a MRP}

I hereby declare that I am the sole author of this MRP. This is a true copy of the MRP, including any required final revisions.

I authorize Ryerson University to lend this MRP to other institutions or individuals for the purpose of scholarly research

I further authorize Ryerson University to reproduce this MRP by photocopying or by other means, in total or in part, at the request of other institutions or individuals for the purpose of scholarly research.

I understand that my MRP may be made electronically available to the public. 


\title{
PLANNING TO CARE: THE CASE FOR A BROADER IMPLEMENTATION OF THERAPEUTIC PLANNING
}

\author{
David M. Alton, 2018 \\ Master of Planning \\ in \\ Urban Development \\ Ryerson University
}

\begin{abstract}
Planning does not see itself as a caring profession, yet there are elements of care that underlie the relationship between planners and the public. Therapeutic planning is an emerging approach to planning that has shown promise at building on those elements of care and reimagining planning as healing and transformative for planners and the public. However, therapeutic planning has so far only been used as a specialized practice when planning with indigenous communities. Through an analysis of the literature on planning theory and therapeutic planning practice, this study seeks to build a case for a broader application of therapeutic planning. Key findings of this analysis show that therapeutic planning has the capacity to improve planners' ability to address trauma, conflict and reconciliation. This ends with a concrete set of recommendations to guide the profession in embracing its potential for care.
\end{abstract}

Key words:

An article on urban planning theory and practice, used the key words: therapeutic; planning; caring; communication; profession. 


\section{ACKNOWLEDGEMENTS}

I would like to thank my supervisor, Dr. Pamela Robinson for her understanding, discerning feedback, and thoughtful support throughout the development of this research paper. Pamela's guiding hand was critical in helping me flush out the vision for this paper and ground it in the language and history of the planning profession and its academic tradition. There were many times where in my excitement I would run into her office ranting like a planning revolutionary and Pamela would warmly redirect my passion towards the fertile ground already being tilled by planners before me. It is unfathomable that this paper would be as insightful or as intelligible without her knowledge and experience. I would also like to thank her role as Associate Dean of the Faculty of Community Services for encouraging me to jump into the inter-professional learning environment that sparked the idea for this paper in the first place.

I would also like to thank my second reader Daniel Fusca. As the Coordinator of Stakeholder Engagement and Special Projects in the Chief Planner's Office, he is doing amazing work sparking conversations about how the City of Toronto can better cultivate the planner-public relationship. His professional eye was invaluable in making sure this paper will be the useful guide for practicing planners that it aspires to be.

This research would not have been able to happen without the unique inter-professional environment being fostered in the Faculty of Community Services at Ryerson University. Connecting with fellow students from the departments of Nursing, Social Work, and Early Childhood Education and learning from their academic traditions, showed me the potential for planning to be caring. Planning does not need to reinvent the wheel as there is so much knowledge that can be gleaned from our fellow professionals. I would like to thank Ryerson for making such a learning environment possible and Dr. Jasna Schwind for being my guide in this wonderful new world. 


\section{TABLE OF CONTENTS}

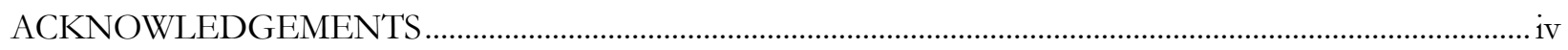

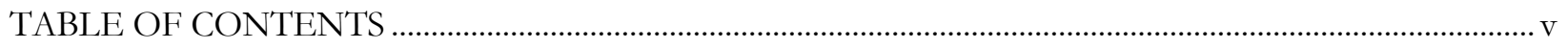

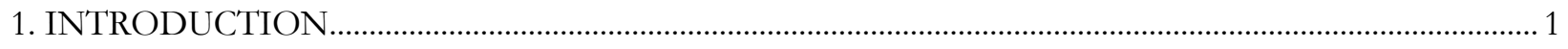

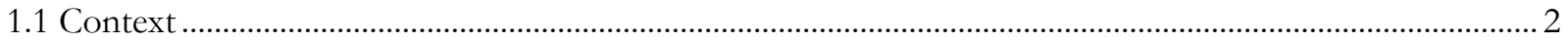

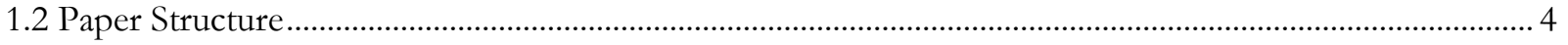

2. UNPACKING THE PLANNER-PUBLIC RELATIONSHIP.................................................................... 6

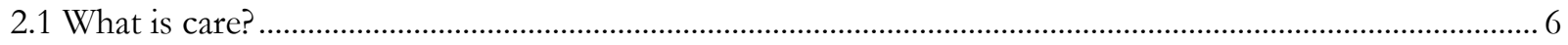

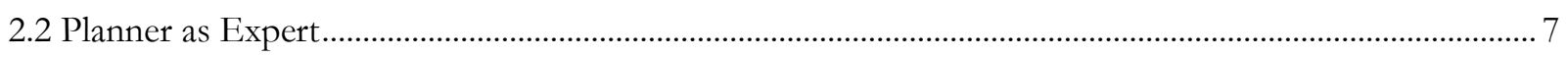

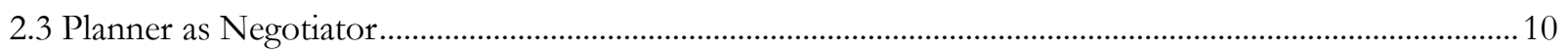

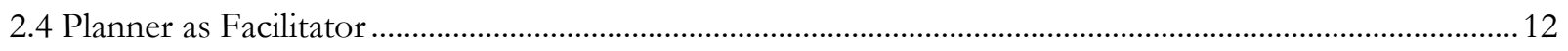

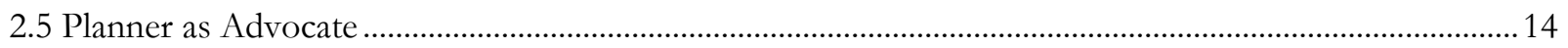

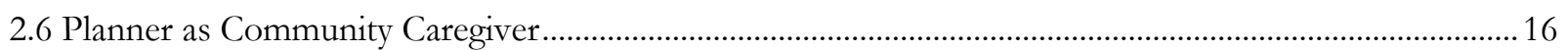

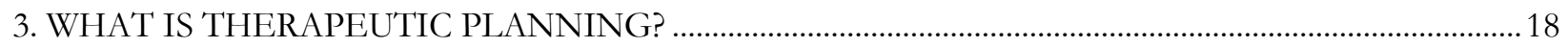

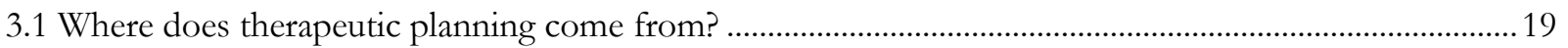

3.2 Does therapeutic planning have applicability more broadly? ......................................................................2 20

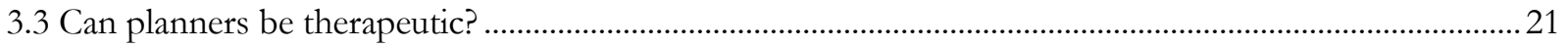

4. THE CASE FOR A BROADER APPLICATION OF THERAPEUTIC PLANNING …….....................25

4.1 Planners have a responsibility towards reconciliation with indigenous peoples........................................25

4.2 Planners need to be better equipped to mitigate and transform trauma .....................................................28

4.3 Planners need to be better equipped to shepherd communities through change ….....................................30

4.4 Planners need to be better equipped to mitigate and transform conflict ......................................................33

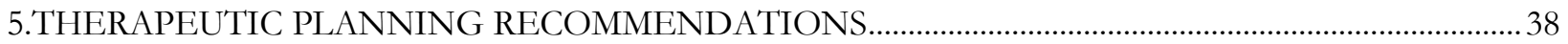

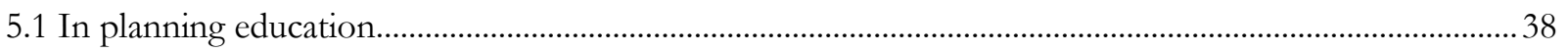

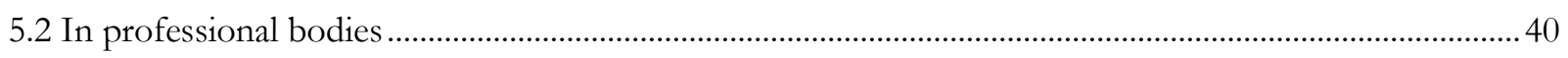

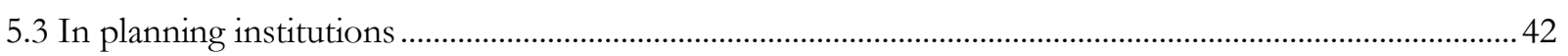

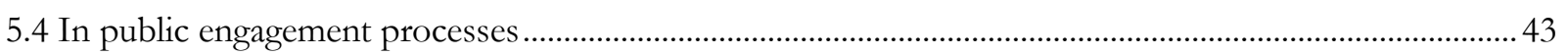

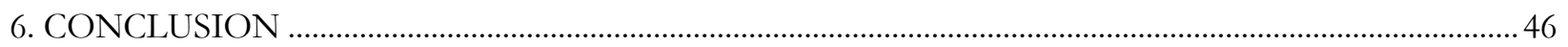

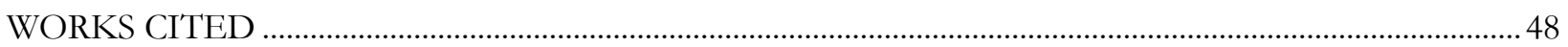




\section{INTRODUCTION}

Therapeutic planning is an emerging theory that highlights the planning profession's potential to be transformative and healing for the public. However, in both theory and practice therapeutic planning is imagined as fringe, as something separate from mainstream planning. In the circumstances where it has been used, therapeutic planning has equipped planners with the language, tools and techniques to transform the planner-public relationship (Sandercock \& Atilli, 2014; Erfan, 2017). Therapeutic planning empowers planners to renew public decision-making processes that are constrained by conflict and trauma. When used in complex societal issues, like reconciliation with indigenous communities, therapeutic planning provides planners with a path forward through tools like recognition, mindfulness, and reflective practice. Where professionals have embraced the caring identity of therapeutic planning both planners and the public have benefited. For example, participants in therapeutic planning processes have reported improved relationships and emotional wellbeing (Erfan, 2017). Building on this legacy, this paper makes the case for all planners to be therapeutic and for planning to become a caring profession.

To support this claim, we must first explore the concept of care in planning and how the planning profession has framed its relationship to the community. While planning has its roots in public health, arising to address the problems of the industrial city, the discipline has largely separated itself from being identified as a caring profession. That being said, planning is fundamentally people-oriented and the relationship between planners and their communities has a rich history that is still evolving today. An emerging imagination of the planner-public relationship that pushes the concept of care to the forefront is found in therapeutic planning. In practice, therapeutic planning has seen measurable success with indigenous communities but has seen little application in broader planning practice. This paper builds the case for all planners to embrace therapeutic planning and provides a conceptual guide for how this could look like in practice. 


\subsection{Context}

The inspiration for this paper was found in a therapeutic communication course I took at Ryerson University in the spring of 2017. The course was rooted in inter-professional education; meaning that it was open to all students within the Faculty of Community Services, which includes Nursing, Early Childhood Studies, Social Work, Nutrition, Child and Youth Care, and Urban Development. Ryerson is one of the few urban planning schools that is located alongside such caring professions as opposed to more traditional disciplines like engineering, architecture, geography, applied science or environmental design. The unique arrangement of the Faculty of Community Services only arose because of Ryerson University's winding history bridging applied and academic education. The Faculty of Community Services is comprised of the degree programs that existed in the 1970s during the first phase of Ryerson's transition from technical school to university (Amborski, 2018). Essentially, the Faculty location of Ryerson's urban planning school arose by chance; However, given my positive experience in the therapeutic communication course, perhaps there is more to the relationship between planning and the caring professions than the Faculty realizes.

The novelty of Ryerson's planning school situation is representative of the current tension within planning's professional identity over the planner-public relationship. At the time, I was the first and only urban planning student to take an inter-professional course in the Faculty of Community Services. This experience raised several critical questions: Why had other planning students not taken this class before? Were there logistical hurdles or is learning about therapeutic communication not as big a priority for planning students as it is for those in the caring professions? Following that, what exactly does it mean for a profession to be caring? Is planning a caring profession? If so, how does caring fit into planning pedagogy and practice? If not, why does planning resist care? And, what could the profession gain from embracing a therapeutic imagination? 
The richness of these questions became immediately apparent as I engaged in the interprofessional environment of Ryerson's therapeutic communication course. My classmates from the caring professions came from disciplines that have well established theories of care such as Nightingale's theory of caring (1989), person-centred care (McCormack, 2003), and relational care (Doane \& Varcoe, 2007). Where is planning's theory of care? Is it embedded in professional ethics? Or in planning theories like the rational comprehensive model or communicative planning? Is the provision of care an important enough element of planning, for the profession to have a theory of care in the first place?

Beyond theory, the caring professions have created models of practice to embody caring into their professional identity. For example, in the therapeutic communication course, we covered such techniques as: reflective practice, mindfulness, person-centred care, narrative therapy, coaching, nonviolent communication, acceptance and commitment therapy, cognitive behaviour therapy and dialectic behaviour therapy. These techniques are a sample of the progress that the caring professions have made at applying and expanding a theory of care into serving individuals and communities. While planning does not have a theory of care, are there any elements of care in planning practice? There seems to be an opportunity for care in planning as many of the techniques of therapeutic communication (reflective practice, non-violent communication, coaching) could easily be incorporated into current practice. Some planners have already begun experimenting with these techniques laying the groundwork for planning to become more of a caring profession (Schön, 1983; Forester, 1999; Forester, 2009).

The most developed of these attempts is the emerging theory of therapeutic planning. It was first introduced by Leonie Sandercock in their book Cosmopolis II: Mongrel Cities in the $21^{\text {st }}$ Century. Sandercock described a therapeutic imagination that saw planning as capable of not only "bringing people together to share their experiences and work in solidarity, but also to work through 
their differences in transformative ways" (2003). Sandercock later expanded this imagination into a full-fledged planning model, which has recently been picked up and explored by Erfan (2017) and Schweitzer (2016). While therapeutic planning is an emerging model, it has currently only been applied to situations where the planning process is explicitly intersecting conflict, trauma or reconciliation with indigenous communities. But what about planning more broadly? Should planning embrace the therapeutic imagination and become an explicitly caring profession? This question is the focus of this major research paper, which will be explored through a literature review as broken down below.

\subsection{Paper Structure}

A major theme of this paper is the relationship between planners and their community. Section 2 will examine the different ways planners have configured their relationship to the public through a literature review of planning theory. In particular it highlights the planner as expert (rational planning), planner as negotiator (incrementalism), planner as facilitator (communicative/ collaborative planning) and planner as advocate (advocacy planning/communicative action).

Section 3 will explore the emerging orientation of therapeutic planning and outlines how the planner can become a community caregiver based on the current research by therapeutic planners.

Section 4 will build the case for implementing therapeutic planning more broadly. Therapeutic planning provides the profession with tools to better address indigenous reconciliation, community trauma and conflict than current planning practice. Planners have an ethical responsibility to better address these elements given the professions past and current actions. The nuances of this responsibility and opportunity provide a strong rationale for planning to embrace a therapeutic and caring identity.

Lastly, section 5 provides a roadmap for how a broader implementation of therapeutic planning could look like. I outline a therapeutic approach to planning education, professional bodies, 
planning institutions, and public engagement processes. Through this paper planners will understand both why and how they should adopt a therapeutic approach. 


\section{UNPACKING THE PLANNER-PUBLIC RELATIONSHIP}

While planning lacks a formal theory of care, it is still fundamentally a people-centred profession. To an outside observer, the city may seem to be the primary muse of planning, but it is the interests of its residents that planners are concerned with. These interests include the public's needs and wants for housing, transportation, community amenities and so on. These interests are often manifested as the "public interest", with the planner as its keeper; a position that is reflected in the professional code of practice (OPPI, 2018). In their exploration of the public interest, planners are thrust into the intersection between the many voices of the public and the voices of expert knowledge (engineers, sociologists, economists...) and of power (politicians). How to navigate these voices and how to frame their relationship to the broader public has been an important inquiry for planners. Over the years planning theorists have constructed several different imaginations of the planner-public relationship. This section will highlight some of the major ones and how they point to elements of care.

\subsection{What is care?}

To understand planning's therapeutic potential let us unpack what makes a profession caring and how that aligns with planning. There is a strong correlation between the caring professions and those associated with health and wellness. We expect doctors, nurses, social workers and counsellors to care for their patients/clients. Do planners have the same expectation? One would think they should, as planning too has a strong connection to health and wellness having arose from the public health movement during the industrial revolution. Communities needed the planner to bring order to the necessities for life (sewer, water, heat, shelter) and to separate communities from hazardous uses (heavy industrial etc.). Current planning interests like active/public transportation, green/blue infrastructure, limiting conflicts between cars and pedestrians, inclusive urban design, and complete communities all seek to improve the health and wellness of the public. Is there a difference between 
the public health objectives of planning and those of medicine or social work? What would happen if planning made its connection to health more explicit? Solving these problems is becoming more relevant as the boundary of health and wellness expands to include more of our socio-emotional lives.

There is clearly more to the caring professions then an interest in health and wellness. Policy analysts and drug manufacturers are both invested in health but are not expected to be caring. These professions do not interact with the public enough to have a clear relationship to care for. This then leads to the crux of caring; it is centred on relationships. Doctors and nurses care for their patients, child and youth workers care for children, social workers care for their clients. Planning is definitely a people-oriented profession. Planners facilitate conversations between stakeholders, they consult and educate the public, they advise politicians, they compile information from a swath of experts. Of these who is planning expected to care for? Developers? Experts and other public servants? City councilors? Residence associations? Town hall meeting participants? Maybe the sheer number of people the planner is expected to interact with overwhelms a theory of care. Unlike the caring professions there is not discrete person the planner is expected to care for. Instead the planner is faced with a heterogenous community. What does community level care look like in practice? Do planners care for the public as a whole or individually? An answer to these questions can be found by unpacking the planner-public relationship.

\subsection{Planner as Expert}

Through a literature review of planning theory, I have identified four configurations of the planner-public relationship that act as a foundation for how care could fit into the planning profession. The first configuration we will explore sees the planner as an expert, whose knowledge the public depends upon to assist with decision-making. The planner as expert configuration has existed as long as planning has been professionalized but is perhaps best represented by the rational- 
comprehensive model of planning theory. As laid out by Banfield, the rational comprehensive model frames planning as "a series of acts for the attainment of the end" (1955). The planner earns their expertise by their ability to identify and ultimately implement ends that are in the public interest. To legitimize planning expertise Banfield suggests that planners be comprehensive - able to identify the principal acts by which all the most important ends are attained; and rational - able to maximize the attainment of the relevant ends (1955). By following the steps of the rational comprehensive model, planners are able to subsume Banfield's principles and act as experts on behalf of the public. This mindset is supported by Friedmann:

"Planners claim that their advanced degrees in relevant disciplines and professional fields give them privileged access to scientific knowledge and technical know-how. They claim that this knowledge is generally superior to knowledge gained in other ways (from practical experience for example). In this respect they speak as the true heirs of the Enlightenment" (Friedmann, 1987).

To Friedmann, the rational comprehensive model is adjacent to the scientific model in the Enlightenment tradition through its desire to discern the world as it really is. Planners are experts because the actions they recommend seek to bridge the objective knowledge of science with the actions of the decision-making process. Friedmann presents three layers to this exchange that the planner as expert serves for the public:

1. Planning attempts to link scientific knowledge to actions in the public domain.

2. Planning attempts to link scientific knowledge to processes of social guidance.

3. Planning attempts to link scientific knowledge to processes of social transformation. (Friedmann, 1987)

Planners as experts are able to actionize the knowledge of science into change at the applied level as well as at the higher-level processes of social guidance and transformation. The assumption underlaying this expertise is that the increased understanding of rational analysis allows planners to identify the levers one needs to pull to get the right course of action (Faludi, 1973). This assumption is at the heart of the planner-public relationship in the planner as expert configuration; the public grants the planner expertise by trusting their authority and in return the planner uses that expertise 
to recommend the right course of action to meet the public interest. In this relationship the public plays the role of the feedback system, highlighting the areas that require deeper rational analysis (Faludi, 1973). This public role recognizes the limits of the planner as expert and the need to frame the planning process with a set of assumptions. Faludi describes this assumption setting process as political choice:

"From the point of view of decision-making, political choice is that process by which a community agrees to make those assumptions required to underpin and supplement knowledge so as to arrive at decisions" (Faludi, 1973).

The public uses political choice to decide what ends, what parts of the public interest, should be prioritized while the planner as expert uses tools like the rational comprehensive model to determine the best course of action to achieve those ends. This planner as expert relationship has been solidified through the professionalization of planning and the creation of the Ontario Professional Code of Practice. It outlines how planners are responsible for the public interest, their clients and employer, and other members of the profession. For example, when it comes to the relationship with the public the code instructs planners to:

1.1 practice in a manner that respects the diversity, needs, values and aspirations of the public and encourages discussion on these matters;

1.2 provide full, clear and accurate information on planning matters to decision makers and members of the public, while recognizing both the client's right to confidentiality and the importance of timely recommendations;

1.3 acknowledge the inter-related nature of planning decisions and their consequences for individuals, the natural and built environment, and the broader public interest; and

1.4 identify and promote opportunities for meaningful participation in the planning process to all interested parties.

(OPPI, 2018)

This section of the code begins to show how the planner as expert configuration of the planner-public relationship points to elements of care. In this relationship, caring is embedded in the planner's commitment to the public interest. The public trusts the planner's expertise and the 
planner uses that expertise to recommend decisions that will best advance the needs of the public.

The focus of care is on the outcomes of planning. Like a doctor, who focuses on improving the health of the patient, the planner as expert is concerned with improved outcomes for their community.

Through a lens of care, several parts of this code stand out. For example, section 1.1 centres planning under the principle of respect and includes several aspects of the socio-emotional realm of the public (i.e. needs, aspirations). By following this code, planners are granted status as experts and are afforded the trust of the public. This configuration of the planner-public relationship has played a dominant role in the framing of the profession and its understanding of care as seen by the code of conduct. That being said, there are many limitations to the planner as expert which have spawned the subsequent evolutions of the planner-public relationship.

\subsection{Planner as Negotiator}

The next configuration of planner-public relationship we will unpack frames the planner as negotiator; where the planner is more integrated with the political realm and its communicative expectations. The planner as negotiator arises from the recognition that there are limitations to the planner as expert. In response to these limitations, planners have had to negotiate between the objectives of scientific and technical expertise, and the social dynamics of the political realm. This negotiator role is best exemplified in planning theories like incrementalism (Lindblom, 1959) and mixed-scanning (Etzioni, 1967). For example, in building a case for incrementalism, Lindblom elaborates on the limitations of planning expertise:

"Making policy is at best a very rough process. Neither social scientists, nor politicians, nor public administrators yet know enough about the social world to avoid repeated error in predicting the consequences of policy moves. A wise policy-maker consequently expects that his policies will achieve only part of what he hopes and at the same time will produce unanticipated consequences he would have preferred to avoid. If he proceeds through a succession of incremental changes, he avoids serious lasting mistakes in several ways" (Lindblom, 1959). 
The process of negotiation for Lindblom, is realized through the incrementalization of action. Rather than taking sweeping actions towards planning ends, Lindblom's incrementalism encourages planners to make piecemeal interventions. Limiting the scope of planning interventions gives space for the public to respond to any changes and refine the direction of planning, albeit only through the voices of key stakeholders in the political realm. This space serves as an expansion of the feedback system that was introduced in the planner as expert configuration. Essentially, incrementalism has incorporated the public's feedback earlier into the planning process creating a model of negotiation between the planner and the public about the nature of the outcomes planning is working towards. This thought is expanded upon by Etzioni:

"Policies are the outcome of a give-and-take among numerous societal "partisans." The measure of a good decision is the decision-makers' agreement about it. Poor decisions are those which exclude actors capable of affecting the projected course of action; decisions of this type tend to be blocked or modified later" (Etzioni, 1967).

Etzioni is describing the increased power the public has in the planner as negotiator configuration. While planners are still bringing their expertise to the decision-making process they are balancing it with the increased voices of the political realm. By engaging with the political realm planners get more access to the levers which implement their recommendations. However, there are challenges to planners engaging more with the political realm. Etzioni observes that "the strategy followed is determined neither by values nor by information but by the positions of and power relations among decision makers” (1967). By engaging with the political realm, planners are not just negotiating with the many stakeholders of the public but they are also negotiating with and across systems of power.

Some may feel that planning is ceding too much of its technical expertise by engaging with the political realm. This is a limitation Etzioni feels that planners in democratic societies must accept "because of their greater need to gain support for new decisions from many and conflicting subsocieties, a need which reduces their capacity to follow a long run plan” (1967). From this dynamic, 
Etzioni proposes mixed-scanning as a compromise between the rational-comprehensive model and incrementalism; empowering planners to balance between their roles as experts and negotiators. Planners can use their scientific and technical expertise to get a good understanding of the broader public interest and the best path forward to achieve that end, and then negotiate with the public to determine the most feasible of those paths given the political and logistical realities.

As seen in the planner as expert relationship, the planner as negotiator also points to elements of care through the planner's quest to advance the public interest. However, incrementalism and mixed-scanning recognize that planners cannot achieve the public interest in single large-scale actions but rather through smaller scale interventions and compromises. In these models, planners negotiate with stakeholders to determine what parts of the public interest should be prioritized and how they should best be implemented. Through a lens of care, planners are essentially negotiating how much care a community needs in relation to how much care is feasible to provide.

The act of negotiating adds another layer of caring to the planner's portfolio in that the planner now has targeted relationships with key stakeholders. Care becomes an element of negotiation — fostering stronger relationships as a means of advancing the public interest. Planners care for the public by advancing outcomes in the public interest and they care for key stakeholders, especially those with political or financial power, in the pursuit of realizing those outcomes. The role of power in the planner as negotiator highlights a point of tension that continues to push the planner-public relationship as it evolves into the next two configurations.

\subsection{Planner as Facilitator}

Up to this point, the planner-public relationship has largely been structured as one-sided with planners using their expertise to act in the public's best interest. The public's role has been to respond to the actions of planners through the feedback processes of the rational comprehensive 
model, incrementalism, and mixed-scanning. This next configuration of the planner-public relationship sees the many voices of the public coming to the forefront of the planning process where the planner becomes a facilitator. In this configuration, planners are concerned with creating space for the public in its totality to be heard; often through a focus on public participation processes.

The planner as facilitator is best exemplified by what has been labeled as planning's communicative turn (Sandercock \& Atilli 2014). At the forefront of this communicative turn is Healey's collaborative planning model. Healey frames planning as fundamentally dialectic, a lifelong interplay between technical experts and the interests of the communities they serve (1997). The planner becomes a facilitator of a larger conversation between the public about what are the public's needs and how they can be best accommodated. Healey frames the nature of this larger conversation with the following set of attributes:

1. It should recognize the range and variety of stakeholders concerned with changes to local and urban regional environments...

2. It should acknowledge that much of the work of governance occurs outside the formal agencies of government...

3. It should open up opportunities for informal invention for local initiatives...

4. It should foster the inclusion of all members of political communities...

5. It should be continually and openly accountable...

(Healey, 1997)

Healey's collaborative planning highlights the increasingly complex responsibilities required of the planner as facilitator. Facilitating a space where everyone is heard means being equipped to manage a diversity of voices and being able to open up the decision-making process to allow for a more flexible range of expertise. The push for a communicative approach to planning has arisen because planners have begun to recognize that they need to work with the public in order to access the local contextual knowledge needed to make effective decisions (Fischer, 2000). This includes the knowledge of the day to day experience of the community that is difficult to access solely through planning's technical and scientific expertise. There are other benefits from the facilitator role as 
planners are also able to unearth new knowledge through dialogue and reach a greater consensus on the public interest (Innes, 1998; Innes \& Booher, 2000).

From the perspective of care, these communicative theorists have expanded the concept of care beyond the outcomes of planning. Planners now care for the public throughout the planning process through the methods of public participation. A caring planner in this model is one that is able to get as many voices to the table and one that can create a space for them to be heard. By bringing all these voices together, planners have created space for collaboration and conflict. Members of the public can build each other up or tear each other down. This means that the planning process now concerns the relationships within the public on top of the planner-public relationship.

Planners therefore need to care for the public but also for how the public cares about each other. If members of the public experience participation processes as abusive, for example if their voice is not heard or respected, that reflects poorly on the planner who has created the space and is facilitating interactions between the public. Communicative planning has thus explored how planners could better address emotions (Baum, 2015; Hoch, 2006) and conflict (Bollens, 2006). The more planners explore how to effectively facilitate a complex, heterogenous community, the more the expectations of the planner as facilitator increase to include a larger set of communicative skills. The scale of this communicative environment has pushed planners to develop one more configuration of the planner-public relationship.

\subsection{Planner as Advocate}

The final configuration of the planner-public relationship I found reflected in planning theory is centred on the way planning intersects with systems of power. This configuration sees the planner as advocate; using their position in the decision-making process to advance the interests of members of the public with less power and those who have traditionally lost out in planning 
decisions. The first major example of the planner as advocate role can be seen in Davidoffs advocacy planning, where the focus is on pursuing more equitable planning outcomes (1965).

Davidoff encouraged planning to expand its scope of knowledge to better understand the costs and benefits of planning proposals on all members of the public and in particular marginalized groups. By expanding their knowledge, Davidoff saw an opportunity for planning to play a greater role in social transformation:

"The prospect for future planning is that of a practice which openly invites political and social values to be examined and debated. Acceptance of this position means rejection of prescriptions for planning which would have the planner act solely as technician" (1965).

Davidoff is not advocating for the rejection of planning expertise, but rather for an expanded scope of that expertise. Technical expertise can be used to produce varied outcomes for different segments of the public. Paring technical expertise with more understanding of the social context, particularly as it relates to the dimension of power, can allow planners to better wield their expertise to more equitable ends. Davidoff says that the "relative ignorance of social and economic analysis has caused planners to propose solutions in the absence of sufficient knowledge of the costs and benefits of proposals upon different sections of the population" (1965).

Communicative planning theorists have also explored the potential of planners to be advocates. Public participation processes are often seen as venues to advance equalization (Hillier, 2010) and as a means of empowerment (Anderson, 2007). For example, Hillier describes public engagement as "a process in which hierarchical steering by power is excluded and substituted by cooperating networks" (2010). The idea is that in a carefully curated space, planners can help the public communicate across or even outside of the power structures that divide them. Elling is skeptical that planners can overcome power dynamics solely through facilitative relationship as outlined in Healey's collaborative planning (2017). Instead they argue that the planner must take a more active role in public participation processes to counter the systemic power of things that 
enforce inequality like capitalism and globalism. These communicative action theorists implore planners to pursue not only more equitable outcomes but also more equitable processes.

The connections between the planner as advocate configuration and elements of care are more immediately apparent than the previous three. There is now an added layer of responsibility to planning's relationship to care as the planner as advocate recognizes that the public is comprised of power imbalances and inequalities. Caring for the public interest then, involves providing targeted support to marginalized members of the public, even at the expense of other members of the public that have more privilege. Planners care for these marginalized members of the public by amplifying their voices and perspectives. Planners are also required to cultivate a greater sensitivity and potentially some more clinical communication skills to accurately understand what marginalized people need in a way that does not further any trauma or loss of autonomy.

The targeted lens to caring that was introduced by advocacy planning is also now being applied in public engagement processes. Every interaction of the planner-public relationship is an opportunity for the planner to create more space for marginalized voices and to advocate for their interests. This means that caring requires planners to be more thoughtful in the design and approach of engagement process so that they become channels for equity on top of information gathering and discourse. By taking an advocacy role, planners wade deeper into the legacies of conflict and trauma that bisect communities. As planners move in this direction, it raises the question whether planners are equipped to manage these complex social spaces.

\subsection{Planner as Community Caregiver}

Throughout its history, the planner-public relationship has continued to expand to provide better care for the public even if the profession does not have an established discourse on care. While none of the configurations of the planner-public we explored explicitly mention caring or a theory of care, there are clear elements of care woven into them that become apparent when one 
approaches through a lens of care. As experts, planners are able to define the public interest and map out the best way for society to achieve it. Caring is embodied in the pursuit of the best outcomes and is a key stipulation of the public's trust in the profession.

Moving into the negotiator role has allowed planners to root improved outcomes in the realities of a heterogenous society. It also has emphasized the relational side of planning's caring. Planners care with the public not just for the public. The facilitator role has expanded on that relational element, creating space for more voices to be considered and has given the public more of a say in its care; Meanwhile, the advocate role has opened the door for planners to care for more than just good outcomes or better relationships. The planner-public relationship has become a venue for communities to build counter power and advance equity. The advocacy role points out that there are auxiliary benefits for the public when planning embraces more of a caring role. What happens when this is pushed even further into a community caregiver role?

Planners have already begun moving toward this area through an exploration of the profession's relationship to the emotional realm (Baum, 2015; Hoch 2006). Planners tend to resist emotion, but when they do embrace it there is the potential for further public benefits as seen in the case studies of Forester (2009). If the profession deliberately embraced a therapeutic planning mindset, it could provide a pathway for planners to become community caregivers alongside a set of concepts and skills to better address the complexity of the planner-public relationship. If planners are encountering challenges in their relationship to the public, especially if they see themselves as experts, negotiators, facilitator or advocates, perhaps it is time they more seriously considered the caregiving capacity of therapeutic planning. From this literature review we have seen how elements of care have been an implicit part of the planner-public relationship since its beginning. Now we will shift our focus ahead, to the new planner as community caregiver configuration that is emerging in the theory and practice of therapeutic planning. 


\section{WHAT IS THERAPEUTIC PLANNING?}

The previous section explored the history of planning theory and laid the foundation for planning to become a caring profession. On top that foundation we will now unpack what therapeutic planning entails, how it has been used in planning theory and practice so far, and how it allows planners to assume a community caregiver role. Such understanding is important as therapy has traditional held a dirty connotation within the planning world, occupying the lowest rung of Arnstein's later of participation (1969). Sandercock tries to reappropriate the term moving away from Arnstein's placating definition to one that encompasses the transformative potential of thoughtful professional/client interactions. The gist of this reappropriation is a shift from therapy as oughts and shoulds to therapy as exploring what could be (Schweitzer, 2016).

At the birth of therapeutic planning Sandercock claimed that "with a successful therapeutically oriented approach to managing our co-existence in the shared spaces of neighbourhoods, cities and regions, there is capacity for collective growth" (2003). Sandercock was making parallels to the potential for healing and growth that people experience from the caring professions. Could a similar transformation be possible at the community level? A more detailed framing has formed in Sandercock's subsequent visits to the model. Therapeutic planning entails:

1. Recognizing that the past is often very present in planning conflicts.

2. Recognizing that past injustices shape what is possible in the present and often prevent constructive solutions from emerging.

3. Providing a process for collective recognition of these tensions and for working through these historic wounds and memories.

(Sandercock \& Atilli, 2014)

The goal of this framework is twofold: at the process level it clears away barriers of conflict

and trauma to create space for decision making; at the individual level participants in the process will have the opportunity for healing and improved mental health and wellbeing. Erfan elaborates on this approach: 
"Therapeutic Planning is not a manipulative make-them-feel better tactic, nor is it a formal cure-them-all approach. Therapeutic planning is emotionally engaged planning, which intends to support a process of healing and reconstruction of meaning. It is a dialogical, rational, embodied and collaborative process that brings community members together and creates conditions for them to work through collective traumas" (2017).

Erfan is quick to place therapeutic planning in the rational decision-making process. Creating space for conflict and trauma allows for decisions that better reflect the emotional needs of the community. It creates an experience between members of the community, stakeholders and government where their pain is acknowledged, further harms are actively mitigated against, and the opportunity for healing is presented. Sandercock's fascination with community healing is that it opens the door for social transformation; "a process of public learning that results in permanent shifts in values and institutions" (2003). The capacity to facilitate such shifts open pathways for planners through complex social problems and allows them to better actualize the public interest. Since the public interest occupies such a central role in the planning profession's identity and code of practice, therapeutic planning is an opportunity for the profession to better realize its own vision. But is planning ready to be a transformative force? Is there room in the development application process or the secondary planning process for healing and social transformation?

\subsection{Where does therapeutic planning come from?}

The original example of therapeutic planning in action that inspired Sandercock's imagination was Wendy Sarkissian's work on the Redfern redevelopment in Sydney, Australia. Recognizing the conflict and trauma surrounding indigenous and settler populations in Redfern, Sarkissian shifted the traditional development planning process to create room for a speak out - a safe place for everyone's voice to be heard (Sandercock, 2003). Here the speak out became a process for community wide recognition that allowed deep seated emotions to shift creating space for new solutions to be entertained. Sandercock \& Attili (2014) later explored arts-based tools to make similar interventions when planning with indigenous communities in British Columbia. Erfan has 
also explored therapeutic planning in an indigenous community planning context where they used a communicative tool called deep democracy. By taking this intentionally therapeutic approach, they found that there was a noticeable therapeutic effect:

1. Participants were willing to engage emotionally and share deeply.

2. Participants improved their interpersonal relationships and sense of community.

3. Participants turned feelings of victimization into empowerment.

4. Participants successfully negotiated internal struggles connected to their trauma.

5. Participants used the language of healing in describing the project. (Erfan, 2017)

These initial forays into therapeutic planning seem to have been effective in incorporating healing, community building and individual empowerment into the planning process - creating an emerging sub-practice within planning. However, these efforts have been cloistered to the planning of indigenous spaces, specifically indigenous social planning. One of the reasons for this focus is because the reconciliation process explicitly calls for collective traumas and historic conflicts to be addressed in order to create space for healing and growth. Therefore, there is a natural alignment between the goals of therapeutic planning and reconciliation planning. Planning with indigenous context is a small fraction of the work the planning profession does. Is there space in these other contexts for therapeutic principles and practices? Does therapeutic planning have applicability more broadly?

\subsection{Does therapeutic planning have applicability more broadly?}

When Sandercock first introduced the therapeutic imagination, it was for "when the parties involved have been at odds for generations, or come from disparate cultural traditions, or where there is a history of marginalization" (2003). These may seem like extreme circumstances, but Sandercock was writing about our increasingly multicultural and heterogenous world. Can planners continue to act under the assumption that the community is free of conflict and trauma? Or that conflict and trauma do not interact with the world of planning? Sandercock claims that "all parties in 
planning disputes have stories" (2003). Until those stories are heard, can the community move forward?

Erfan also focusses on a broader set of stories than those just found in situations of extreme loss or conflict. They point to Peter Marris (a hugely influential thinker on loss and change who this paper will explore more later) and how the process of community change causes trauma. "There is a parallel between the stories of personal loss and grief, and collective loss and grief brought on by social change" (Erfan, 2017). If planners are often stewards of change in communities, do they not then have a responsibility to the trauma that change triggers in the public? Erfan thus recommends that planners: increase their understanding of the experience of grief, create space for that grief where they can, and employ therapeutic planning to process that grief (2017). In their view, therapeutic planning should be something that all planners are aware of and understand but is a process that is administered by specialized therapeutic practitioners.

The reason for this separation between planners is that therapeutic planning requires a specialized set of skills around trauma and conflict management that take a significant effort to master. However, does this distinction also separate therapeutic planning from planning as a whole? Sandercock \& Atilli also touch upon this tension. They ask "are we overstepping our professional boundaries by even using the term therapeutic planning and trespassing in the realm of psychologists" (2014). What these authors are really asking is if there is room in planning's professional identity for therapeutic planning? Are the values and skills of planning so outside the realm of the caring professions that embracing therapeutic planning is something better suited to another discipline?

\subsection{Can planners be therapeutic?}

One cannot dismiss the concerns about whether therapeutic planning is overstepping planning's professional boundary. However, it is unclear whether there is another field already taking on the community-caregiver role. Sandercock \& Atilli, despite their concerns, also wonder that if planning 
is "about negotiating a relationship between the past and the future, a relationship that is often fraught with tension, conflict, and trauma, then perhaps planning is the ideal forum for talking about trauma and healing" (2014). The spaces in which we live often become vessels for a community's emotions. Since planning explores the transformation of these spaces it also touches upon the transformation of these emotions. Erfan sees planners as being well suited to the role of community healing because planning:

1. Is a relatively accessible collective and public activity.

2. Lends itself well to negotiating a relationship between the past and the future.

3. The practical and tangible aspects of planning discourse keep the space grounded compared to more directly emotional conversations.

4. Often has less baggage with marginalized populations than other caring professions. (2017)

The second and third point are really important to emphasize. The second pulls back to the experience of change and the emotional dimensions that it triggers. By hosting discourse on change planning is able to bridge the traumas of the past to the potential for transformation that lies in the future. The third point is referencing the challenges surrounding direct conversations about trauma. Talking about experiences of harm can seem too scary or intense for people. However, once those feelings are housed in something tangible like a bike lane or a specific building they become easier to work with. Erfan elaborates on this effect:

"Many planning discussions make a good doorway into healing - if held with the intention to heal - because they link the internal and external conflicts and historic traumas to tangible things that are relevant to people's lives today" (2017).

If therapeutic planning has been shown to be beneficial in planning with indigenous communities, and if the planning process is well suited for community scale healing, what does it mean for the profession to fully embrace the therapeutic imagination? Schweitzer has begun laying out this ground work by exploring how planners in public institutions can approach community harm, in particular the harm caused by the profession. They lay out three professional duties for planners looking to become more therapeutic: 
1. Deliberate with individuals and groups who have experienced harms and wrongs, and to explore both a) the calls for the remedy of those with the tools of ordinary justice and b) forge collective understandings of what constitutes harms and wrongs.

2. Foster within agency dialogues regarding remedy for individuals and groups that have been harmed and, in turn reform the institutional practices such that they align with the norms and values of the wronged and the larger political community, depending on the context.

3. Echo and support efforts at transformation within the broader political community so that its norms and values begin to align with those of the wronged.

(Schweitzer, 2016)

The deliberation in Schweitzer's first point aligns with the practices Sandercock, Atilli and Erfan have explored to process community trauma and conflict. The second point adds in the principles of reflective practice, which encourages professionals and the institutions they represent to reflect on their role in systems of trauma and conflict. Reflective practice is already encouraged in other caring professions (Doane and Brown, 2010). Schweitzer's third recommendation points to the idea of planners as advocates on behalf of the marginalized for social transformation. While planners may value being seen as unbiased actors, they exist in a society that is filled with cycles of trauma and conflict, and often work for institutions that have contributed to those cycles. By becoming an advocate for transformation and by fully embracing their role in societal trauma, planners create space for healing to occur.

Therapeutic planning is an emerging practice within planning. So far it has been used in practice only by a few planners working with indigenous people in British Columbia (Sandercock \& Atilli, 2014; Erfan, 2017). While there exists little research on the application of therapeutic planning, what has been done has shown that therapeutic practices have been effective in indigenous social planning and have led to greater feelings of community cohesion and even healing. The champions of therapeutic planning have pointed to greater applicability in the world of planning at large; However, questions remain about how therapeutic practices fit into the identity and skill set of planners. Schweitzer sees an opening in planning at large by pairing therapeutic techniques with reflective practice and advocacy (2016). To do this means a dramatic shift in current conceptions of 
planning from one of solving problems through rational tools to a profession that actively cares for and with communities. To support this shift, the rest of this paper will elaborate on why all planners should be therapeutic and will provide a roadmap for how this can happen. 


\section{THE CASE FOR A BROADER APPLICATION OF THERAPEUTIC PLANNING}

While therapeutic planning is rooted in the tradition of communicative planning, it pushes the profession further by bringing reconciliation, conflict and trauma to the forefront of the planning process and making an ethical claim for planning as the public's arbiter of community change. This section builds the case for a broader application of therapeutic planning. It highlights how therapeutic planning presents an opportunity for planners to overcome some of the challenges of the planner-public relationship. Therapeutic planning frames community healing and transformation as a central objective for planners and gives them the tools and language to address such challenges as irrational/emotional responses and stakeholder conflict.

There is an also an ethical responsibility for planners to become more therapeutic. Planners have a role to play in many of the challenges of community decision making. These challenges are further exacerbated by planning's contributions to colonization and to the public's experience of trauma and conflict. If planners are serious about caring for the community, they need to transcend the roles of expert, negotiator, facilitator and advocate. It is time for planners to see themselves as community caregivers with the responsibility and ability to foster community healing and transformation.

\subsection{Planners have a responsibility towards reconciliation with indigenous peoples}

In its current implementations therapeutic planning has been primarily focused on planning with indigenous communities where the responsibility to reconciliation is most needed and most apparent. Indigenous planning prioritizes "long-term learning, the empowerment of community voice, and the advocacy of culture and tradition" (Jojola, 2008), which creates space for the sociopsychological health and healing. The community planning process is well suited to meet some of the objectives of reconciliation (Jojola, 2008; Matunga, 2013); a claim that is further supported by the emerging practice of therapeutic planning (Erfan 2017; Sandercock \& Atilli, 2014).

Reconciliation is a societal responsibility that planners need to incorporate into their practice, 
especially since planners often operate as arbiters of the state. Land-use planning is a central part of the colonization process and community planning has ties to Canada's many attempts at cultural genocide where indigenous people were excluded from the conception of 'the community'.

Planning's role in colonization has been unpacked by many theorists (Jackson, 1998; Jojola, 1998; Porter, 2010; Dorries, 2012), while others have outlined pathways to decolonize the professions (Hibbard \& Lane, 2004; Walker, Jojola \& Natcher, 2013). As planning seeks to move into postcolonial practice there are deep traumas that the profession needs to heal.

The profession is beginning to explore its responsibility to reconciliation through a more liberal approach to the Duty to Consult as seen in Ontario's Provincial Policy Statement increased consultation recommendations when it comes to cultural heritage resources (2014). Professional bodies like the Ontario Professional Planners Institute (OPPI)are also beginning to foster conversation on the profession's role in colonization and how reconcile with that history (Brook, 2017). The Calls to Action stemming from the Truth and Reconciliation Commission (TRC) provide a framework for reconciliation that planners can follow (2015). While the Calls to Action have specific recommendations for other professions like nursing, social work and education, planning is never explicitly mentioned. This is a surprise given planning's relationship to land use control and subsequently colonization. However, there is a call for planners, as public servants, to get educated on the history of Canada's indigenous people alongside training in conflict resolution, human rights and anti-racism.

Given the history of land use in Canada, the legal and ethical responsibility on planners to meaningfully engage with indigenous stakeholders is surely to only grow as the reconciliation process unfolds. This is especially the case when you consider the heterogeneity of indigenous identity in Canada. There are sizable indigenous populations living in urban, suburban and rural areas. Can planners continue to treat planning with indigenous people as separate from general land 
use and community planning? If all planning engages with some dimension of Canada's indigenous community, then the capacity to facilitate reconciliation and healing are primary responsibilities for all planners.

Reconciliation can seem like an insurmountable task for planners. However, that complexity does not mean that indigenous people have not experienced wrongs and harms at the collective and individual level (Young, 2011). How can a profession move forward with a community in the face of these harms? Reconciliation therefore, is a necessary prerequisite for professional activity. To crack through the complexity of our colonial history, Derrida frames successful reconciliation as "positive movement in thought that seeks accountability for past wrongs so that they are better understood and can be avoided in the future" (2001). Their framing aligns quite nicely with the goals of therapeutic planning, which gives space for past injustices to be recognized in relation to present activities. In practice, therapeutic planning provides a compelling path forward with its record of improved reconciliation outcomes (Sandercock, 2003; Erfan, 2017). By adopting an empathetic perspective more broadly and increasing the therapeutic communication skills of planners, the profession can become a leader at reimaging the relationship between indigenous Canadians, the public service and the broader Canadian 'community'. As the branch of the state that is most directly focused on mediating public interests, consulting stakeholder groups, and facilitating public visioning, planning is uniquely suited to play a leading role in reconciliation.

The current divide between planning with indigenous communities and the rest of the profession that is supported by Sandercock and company's limited scope of therapeutic planning, underplays the responsibility planners have to reconciliation. Bringing in the tools and perspective of therapeutic planning only in planning spaces that are identified as indigenous enough prevents the rest of the planning system from undertaking the change needed to happen for reconciliation. Planners will invariably interact with indigenous people in most communities. For example, there are 
sizable indigenous populations in many Canadian cities (INAC, 2018). How can planning reconcile with those indigenous people when therapeutic planning is a tool only for specialists in reaction to crisis as suggested by Sandercock (2003)?

Without a broader application of therapeutic planning, planners will continue to perpetuate colonialism and be unequipped to make decisions that advance reconciliation. The separation within planning around reconciliation, also underestimates the healing potential therapeutic planning could have if adopted by the whole profession. The essence of therapeutic panning is a recognition of the past and how it embodies itself in the present through the emotional realm of conflict and trauma combined with a concerted effort to provide space for that emotional realm to heard and healed. This does not mean that every planning activity needs to become a deep dive into reconciliation like the TRC. Some may, but by adopting a therapeutic perspective the rest can still support reconciliation through smaller scale interventions that build into a new culture of healing.

\subsection{Planners need to be better equipped to mitigate and transform trauma}

The reason therapeutic planning is so successful at approaching reconciliation is because of the respect and empathy the approach shows to trauma. Trauma extends beyond the legacy of Canada's treatment of indigenous people. Many of the stakeholders and citizens that interact with the planning process will have experienced trauma - be it personal, social or systemic - and that trauma will influence their experience of planning. It may shape their perspectives or be expressed through emotional displays or hardened into conflicts. In the current panning model there is no formal recognition of this trauma. Any expression of trauma is therefore viewed as irrational, unreasonably biased and an obstruction to decision making. It will be dismissed or if it cannot be, a problem-solving perspective will used to deal with it.

If trauma is such an important part of an individual's experience that it is impacting their involvement in the planning process, why not build problem solving into the process in the first 
place. Therapeutic planning aims to do this by recognizing the role trauma plays, creating space for it to be expressed in the process and equipping practitioners with an empathic approach to trauma. This does not mean that the planner becomes a counselor; helping each participant process their trauma. That would be beyond the scope of the profession and unfeasible at a community scale. However, a lot of the obstacles of planning can be overcome by treating the emotional realm as part of the scope of rationality.

As with indigenous reconciliation, planning has a role to play in the creation of other community traumas and thus a responsibility to mitigate harm and promote healing. There is a dark side to planning (Allmendinger \& Gunder, 2005; Yiftachel, 1998), in which planning tools have been used to enforce and expand economic and social inequalities. One of the way this happens is through the illness narrative that develops when planning labels places as in need of development. This process is documented by Gunder \& Hiller:

"In this role, planners quantify the politically qualitative lack as a measurable symptom. A lack of economic competitiveness thereby becomes a lack of transport-efficient urban form, adequate infrastructure, or available commercial land for development. A perceived lack of safety and security becomes symptomized as high crime rates and antisocial behaviour to be 'cured' through ‘good' urban design” (2007).

Mirroring the doctor-patient model in health care or the counselor-patient model in social work, planners place the burden for change on the communities labeled as underdeveloped, masking their own role in perpetuating harm (Gunder \& Hillier, 2007). The medical profession has shifted to a person-centred model of care because the one-sided doctor-patient model belittles the experience and knowledge of patients perpetuating their feelings of disempowerment and trauma (McCormack, 2003). This shift has begun in planning through the participatory power of communicative planning, but it lacks the lens of healing that creates space for the experience of trauma. Communicative planning shortchanges the empowerment and healing of communities by not encouraging an open exploration of their trauma and planning's role in it. 
To better contextualize planning's role in fostering community trauma we can point to the explicit trauma of slum clearances and relocations (Fullilove, 2004; Marris, 1974; Fried, 1963, Young \& Willmott, 1957). The legacy of these traumas lives on in the cultural memories of the affected communities. Has planning done enough to reconcile with its traumatic past? While it is uncommon for such explicit relocation to happen in modern planning practice, the displacement that occurs with contemporary planning's redevelopment activities arguably achieves the same effect. Sennet traces this problem to planning's preoccupation with idealism and order, a preoccupation that promotes narrow-mindedness and violence (1970). The mindset of the planner as expert who problem solves the city, casts certain experiences of the city (and the people who embody them) as undesirable and in need of change, often in ways that reinforce already established power differentials.

Communicative planning has begun to try and shift this dynamic by including the voices of communities in the problem-solving process, although questions remain about who is included and how much power is shared. Therapeutic planning goes further by putting problem solving in the context of community health and healing. A path to a renewed planner-public relationship has been identified by Posner and Vermuele through their exploration of ordinary justice (2004). They see a potential starting point on this path by exposing the extent and nature of the harms done by planning. This is very in line with the recognition stage of therapeutic planning.

\subsection{Planners need to be better equipped to shepherd communities through change}

Beyond the trauma that comes from planning's explicit and implicit dark side, there is another layer of trauma that is even more fundamental to the profession: the trauma that comes from change. Planners are in many ways the shepherds of change in communities. They attempt to mediate and control effect of change on the present and they prepare plans for the shape and direction of future change. The relationship between change and trauma has been explored through 
the work of Peter Marris (1974). In their seminal work Loss and Change, Marris explores the emotional experience of change. They elaborate how "even desired change can prompt feelings of loss or suffering", feelings that only amplify when the change is imposed by an external authority (1974). Even as planning makes strides to increase the voice of the community and direct change in the community's desired direction, the members are still likely to experience loss.

There is also the acute loss experienced by the community when planning does not or cannot recognize community autonomy or steward desired change. Trauma arises when there is no grieving process to transform these feelings of loss into growth (1974). The trauma associated with community change can be quite significant. For example, residents in insecure public housing situations described the stress of relocation as very unpleasant: "moving three times is the same as having your house on fire once" (Manzo et al. 2008).

Marris dives into the trauma of change further with their exploration of continuity. They explain how individual members of the community will project their sense of security onto the physical community around them and create a series of structures of meaning (Marris, 1974). These structures of meaning remind people of their relationship to the community and how their experience fits into a broader paradigm. When change happens to the community there is not just a loss of specific experiences (i.e. favourite pizzeria, an important view) there is also a loss in the continuity between these structures of meaning (i.e. This is a safe space, this is my home, I belong here). Having signposts of continuity either in the physical community or in the process of change can help mitigate feelings of loss (Marris, 1974). When loss does occur in community change, people need space to grieve in order to rebuild their continuity of meaning. Marris explains the dynamics of this grief as such:

"Grief, then, is the expression of a profound conflict between contradictory impulses - to consolidate all that is still valuable and important in the past and preserve it from loss; and at the same time, to re-establish a meaningful pattern of relationships, in which the loss is accepted" (1974). 
This tension between the meaning of the past and the future is reflected in the challenge of community engagement in the planning process. For example, when advocates within the community push for "some phantom of the past projected onto some future utopia at the cost of disavowing the unhomely reality of living in the present" (Donald, 1999). Without a proper grieving process, communities are unable to move on from the past and let go of their fear of the future and are thus stuck in a state of trauma. As curators of change, Marris gives planners several recommendations to mitigate loss, preserve continuity, and allow for grief and thus healing and growth to arise:

1. Provide ample advanced notice so community has time to prepare for change.

2. Retain key physical, social and procedural features to signify continuity.

3. Expect and encourage public conflict so people can express and process their emotional reactions.

4. Place a moratorium on more change until initial change has been processed so as to not emotionally overwhelm community.

(Marris, 1974)

In the years since Marris' work, many of his recommendations have come to pass. The requirements for the type and length of notice have grown, and long range/predictive planning activities have tried to give communities more preparation and autonomy over future change. Similarly, the rise of the heritage preservation movement has cemented continuity as an important factor for consideration in planning. Marris' last recommendation is reflected in proposals such as the City of Toronto's one-year moratorium on high rise development in the downtown core. After an influx of condo development in the downtown core, counselor Kristyn Wong-Tam inquired into the feasibility of a development moratorium to give planners and the public more time to understand how the development would fit into the public interest (City of Toronto, 2016). The request was pulled and the moratorium dropped, reflecting how the rate of change in many communities is too great to feasibly realize Marris' vision. Marris' third recommendation is where I see the biggest gap in current planning practice but also the biggest opportunity for therapeutic 
planning. Therapeutic planning essentially builds and expands this point by creating a respectful space for trauma, the grieving process, and the conflicts that stemmed from them to be recognized and processed.

Both Marris and the therapeutic planners that followed them make the case for the emotional wellbeing of communities to be a top priority for the profession. The profession has a responsibility to become more therapeutic because not only does planning have a traumatic dark side but the process of change at the heart of the profession is inherently traumatizing. Therapeutic planning encourages planners to be mindful of their potential to be agents of either trauma or growth and gives them a path to choose the latter. Therapeutic language, an approach rooted in person-centred or community-centred care and built in grieving processes, is one of the tools available for planners to assume their potential for community growth and transformation.

\subsection{Planners need to be better equipped to mitigate and transform conflict}

Conflict is another element of the planning process that the profession has struggled to deal with. Whenever a harm or wrong occurs it can be hard to discern the path to reconciliation given the multiplicity of actors in public disputes (Digeser, 2001). Marris also points out how conflict interacts with the grief process where the loss of continuity leads to the various community members seeking a new source of meaning through conflict. To better understand how grief is resolved, Marris examined mourning rituals and found that they recognize three important elements:

1. Loss generates a conflict which must be worked out, so as to restore a vital sense of continuity to experience.

2. The resolution of this conflict cannot be preordained, since the resolution only becomes meaningful through the ambivalent exploration by which it is realized.

3. Until grief is worked out the conflict itself becomes the only meaningful reference for behaviour.

(Marris, 1974).

Like the cultural mourning rituals Marris studied, institutions need to embody these principles to be able to respond to societal and community change (1974). This call for a renewed 
relationship between institutions and conflict has resonance in planning as many researchers have found a culture and process that promotes conflict and inhibits its transformation (Hillier, 2002; Pløger, 2004). Many planning decisions create competing sub groups of the public and force them to embrace decisions that often do not embody their preferences. An example of this can be seen in the contentious process of locating services like homeless shelters. Limited resources, restrictive bylaws, and policy obligations create a planning environment where communities are provided few options to respond other than conflict. Given this environment, the location of new shelters is often decided by feasibility (i.e. where bylaws and funding allow) as opposed to the interests of streetinvolved people or the surrounding community.

Conflict also plays out in the development application process where the different members of the current community and future community struggle to find a voice in the conversation between developers, city planners and other key stakeholders. With so many voices and only a few key points of intervention via public meetings, it is no wonder participants entrench their opinions and project their feelings of loss onto one another. The most prolific example of this dynamic is in NIMBYism and its critics. What other choice does a community apprehensive of change have than to attack the future community or development proposal who they see as representative of that change?

The current process provides little space for the emotional turmoil fueling NIMBYism to be spoken, affirmed and redirected towards renewed continuity and emotional growth. At the same time there are layers of power and intersections of privilege and marginalization that run through the community bringing broader conflicts about voice and belonging into the space. These broader societal conflicts are also not given space within planning and so they get manifested as exclusion and disengagement. Many groups have lost trust in the planning process to represent their interests and will not participate in long range activities like secondary plans and official plans. In response, 
movements like advocacy planning have arisen to raise awareness of the profession's responsibility to counter power conflicts. Instead, taking a therapeutic approach may be preferred because its processes of recognition and reflection awaken opportunities to transform and transcend those power conflicts.

Planners are part of larger social systems and exist in a complex conflictual relationship between the political realm, their professional responsibility and the desires of developers. Conflict has become so accepted in the profession that for many planning decisions it is just expected that they will need to be resolved through some form of arbitration such as at the Ontario Municipal Board (Pagliaro, 2016). The planner is thus stuck navigating three levels of conflict, the individual conflicts between participants struggling to process change and trauma, the systemic conflicts that enforce and dismantle structures of power, and the internal conflicts between developers, politicians and planners at the heart of the profession. Bollens unpacks the unique role planning plays in regard to the conflicts within our city:

"The city is important in peace building because it is in the streets and neighborhoods of urban agglomerations that there is the negotiation over, and clarification of, abstract concepts such as democracy, fairness, and tolerance. Debates over proposed projects and discussion of physical place provide opportunities to anchor and negotiate dissonant meanings in a post-conflict society; indeed, there are few opportunities outside debates over urban life where these antagonistic impulses take such concrete forms in need of pragmatic negotiation" (Bollens, 2006).

As found by Sandercock and company, it is the applied aspect of planning conversation that allows the emotions of conflict to be grounded in the concrete aspects of our everyday lives. Planners have not been oblivious to this potential for the profession to transcend its conflicts and play a peace-building role. There have been several frameworks and tools proposed such as LeBaron's conflict transformation approach to help planners bridge cross-cultural conflicts (2003). There is also the transformative mediation method which like therapeutic planning is centred on the pillars of empowerment and recognition (Bush \& Fulger, 1994). The idea in all these tools is that 
conflict cannot be resolved through a top down approach, it requires participants to be heard and valued. Only through such a process of ambivalent exploration can a meaning beyond conflict be uncovered (Marris, 1974). Marris outlines a set of principles for the management of change. Planners should:

1. Expect and encourage conflict so participants have an opportunity to react to change and articulate their feelings.

2. Recognize the autonomy of different types of experience to allow people to self-organize their own experience of grief.

3. Give time and practice patience so that the transformative process can occur. (Marris, 1974)

Therapeutic planning aligns with the community conflict resolution theory and practice of Bollens, LeBaron and company. It recognizes that conflict is a part of planning and that it is rooted in real feelings stemming from the loss of change, deep seated traumas, and systemic power imbalances. Therapeutic planning counters the power dimensions of conflict by empowering all participants to express their emotional experience and then grounds these emotions in the practical questions of what change will actually look like in the community. Such a process does not make planners community therapists or mediators; nor does it mean that planning will be the salve to all conflict and trauma in society. Instead, therapeutic planning recognizes the role planners play in community conflict and trauma, and in particular, the potential for planning discourse to ground abstract emotions and direct them towards growth reconciliation and healing.

This can be seen in Wendy Sarkissian's intervention in Redfern where the conflict between the indigenous and non-indigenous communities was overcome when the emotional realm of all participants was heard and affirmed (Sandercock, 2003). The speak out activity transformed abstract societal conflicts as well as more personal tensions and anxieties into understanding and a common language. The practice of therapeutic planning that Sandercock crafted from Redfern creates a common framework that everyday practitioners can use to turn conflict into both a more productive 
decision-making process and even a process that leads into greater community cohesion and wellness.

The goal of this past section has been to make clear the potential therapeutic planning has to reimagine the profession if applied more broadly. Planning should become more therapeutic because it makes the process more productive. It transforms conflict and emotional deadlocks into common understanding, thus making the public interest easier to identify and actualize. The decisions that come from a therapeutic approach better reflect the needs of the community because they recognize the emotional realm and different expressions of knowledge as real and rational. Therapeutic planning therefore better assists planners in achieving our professional commitment to identify and actualize the public interest. Section 1.3 of the Code in particular calls for planners to acknowledge the inter-related nature of planning decisions and their consequences for individuals, the natural and built environment, and the broader public interest (OPPI, 2018). The reflective and emotionally attentive approach of therapeutic planning makes it easier for planners to embody this part of the code as well as others.

There is also an imperative for planning to become more therapeutic because of the legacy of conflict and trauma that are caused by planning's dark side. Nowhere is this transformation more important than on the indigenous reconciliation front. If planning is to truly reconcile with indigenous communities, it needs to replicate the successes of therapeutic planning throughout the profession. Indigenous reconciliation, trauma and conflict are fundamental parts of planning that no professional can ignore. Therapeutic planning puts the healing of these dynamics at the forefront of planning's objectives. Planners can and should care for their communities. Therapeutic planning creates a theory of care that reimagines planners as community caregivers. If the therapeutic imagination grants planning the capacity to be healing, what is stopping the profession from embracing this therapeutic potential? 


\section{THERAPEUTIC PLANNING RECOMMENDATIONS}

To assist planners in conceptualizing what therapeutic planning could look like in their practice, this section evaluates four core elements of the planning profession and imagines several practical interventions that the field can take. It provides concrete recommendations for planning schools, professional accrediting bodies, planning firms and municipal planning departments on how they could foster a culture of therapeutic planning within the profession. This section also provides recommendations for individual planners when approaching public engagement activities like public meetings. By following through on these recommendations planning can take some confident steps forward into becoming a caring profession.

\subsection{In planning education}

Planning education plays an important role in the process of actualizing a broader application of therapeutic planning. As the gateway into the planning profession, it frames how the next generation of planners will approach the planner-public relationship. When it comes to social sensitivity training like therapeutic planning, Agyeman \& Erickson see planning schools as "uniquely positioned to equip future generations of planners with well-intentioned aspirational principles and ideals but that these need to be reimagined and embodied as cultural competencies that are essential for planning" (2012). In order for planners to gain a better understanding of how to approach things like therapeutic planning, planning education needs to view caring and the planner-public relationship as a fundamental part of the field. Until planning does so, it creates an educational environment that not only hampers students therapeutic learning but one that deters emotionallyminded people from becoming planners. Baum has observed planning's hostile relationship with emotions and recommends planning schools actively recruit emotionally minded students and staff, for example those with backgrounds in the caring professions (2015). By recognizing caring as a core 
competency and recruiting emotionally minded planners, planning schools can create an environment that fosters the therapeutic imagination.

It will take more than a new recruitment strategy to integrate therapeutic planning more actively into planning education. At the heart of this evolution is a call for a change in curriculum. I have identified two points where therapeutic planning should be integrated into the current education environment. The first involves creating space for a theory of care in planning theory education. This could involve applying a theory of care lens to planning theory - as seen in Section 2 of this paper - or creating a separate stream of planning theory. Either way, space needs to be created for planners to reflect on the importance of the planner-public relationship.

To this end, planning can learn from the other caring professions that have more established theories of care. Doane and Brown advise educators to be "constantly scrutinizing our educative actions to see what theories and truths are governing our own interpretations and approaches with students" (2011). Therapeutic communication education requires such self-reflective inquiry from educators. Without reflective practice, where will planners learn about the intricacies of care? Planning has already started moving in this direction with Schön's reflective practice (1983) and Forester's deliberative practice (1999) but these need to be paired with a more explicit theory of care.

The other element of therapeutic planning curriculum reform involves therapeutic communication techniques. There are many therapeutic communication techniques such as Sandercock \& Atilli's arts-based practices (2014), Erfan's deep democracy (2017), or techniques like non-violent communication and coaching used by other caring professions. Planning students need an opportunity to be exposed to the potential tools available. However, to cement these learnings they also need to be provided opportunities to practice skills in emotional sensitivity, conflict management, reflective practice and mindfulness. Therapeutic practitioners in nursing have found 
that "purposefully designing curricula to include opportunities for student engagement in experiential creative activities that foster and develop personal knowing is one of the key approaches to nurture person centred care qualities in future practitioners" (Schwind et al, 2014). In order to help planning students turn a theory of care into practice, they need the opportunity to engage and experiment in a supportive environment that fosters critical and reflective care. Planning does not need to reinvent the wheel in order to create such an academic environment. There is much that planners can learn from other caring professions about best practices and approaches to therapeutic education.

This paper recommends that planning education institutions:

1. Make the concept of care and the planner-public relationship core competencies required for graduation.

2. Actively recruit students and staff with a background in the caring professions and/or and interest in emotions, conflict, trauma and reconciliation.

3. Incorporate a theory of care and therapeutic planning into the planning theory curriculum.

4. Incorporate training in therapeutic communication techniques into the curriculum and provide opportunities for students to engage, experiment and reflect on their caring skills.

5. Foster academic partnership with caring disciplines like nursing and social work.

\subsection{In professional bodies}

Professional bodies like the Canadian Institute of Planners (CIP) and the Ontario Professional Planners Institute (OPPI) play a large role in setting the profession's identity and objectives. Guiding the work of these professional bodies and thus all planners accredited by them is the Professional Code of Practice. Because therapeutic planning expands the responsibility of the planner to care for communities and to create opportunities for healing and transformation, for it to be applied more broadly calls for integration into the Code of Practice. OPPI's Code is divided into two sections: Statement of Values and Standards of Practice.

When it comes to the Statement of Values, there currently is a call to respect diversity, to foster public participation and to articulate and communicate values (OPPI, 2018). These all point in the direction of therapeutic planning in a manner similar to the communicative turn in planning 
theory. However, to foster a therapeutic professional culture these should be expanded to include an explicit value to create space for community healing and transformation. As for the Standards of Practice, it currently outlines far fewer responsibilities for planners to the public interest than to their clients, employers, the profession and other members. Therapeutic planning pushes the profession into the role of community caregiver - a configuration of the planner-public relationship that demands more responsibilities than are currently applied. The richness of the planner-public relationship as community caregiver should be unpacked further as the profession develops a deeper understanding of care. In the meantime, Sandercock and Atilli outline a strong starting point for a therapeutic understanding of the profession in their description of therapeutic planning:

1. Recognizing that the past is often very present in planning conflicts

2. Recognizing that past injustices shape what is possible in the present and often prevent constructive solutions from emerging

3. Providing a process for collective recognition of these tensions and for working through these historic wounds and memories (2014).

Professional bodies can further support the development of therapeutic practice through training and guidance. The responsibility for a therapeutic education cannot reside solely on planning schools. Nursing has found a burn out problem in person centred-care theory and techniques when they are not implemented by the rest of the profession (Schwind et al, 2014). An effective therapeutic education requires support throughout a planner's career, meaning that CIP and OPPI will play an important role in fostering therapeutic education in practicing professionals. This paper recommends that planning professional bodies:

1. Update Statement of Values to include a call to create space for community healing and transformation

2. Update Standards of Practice to include:

5. Recognize that the past is often very present in planning conflicts

6. Recognize that past injustices shape what is possible in the present and often prevent constructive solutions from emerging

7. Provide a process for the collective recognition of conflict, trauma and colonization and for working through these wounds and memories

3. Provide training in therapeutic planning theory and therapeutic communication techniques for professionals throughout their careers. 


\subsection{In planning institutions}

For therapeutic planning to become integrated into practice, there needs to be leadership from planning institutions like planning firms and municipal planning departments. All of these planning institutions have a mandate, whether embodied as a strategic plan, mission or vision statement, or some other set of policies. There is an opportunity to incorporate the therapeutic imagination by expanding the institution's guiding documents to include elements of community care, healing and transformation. Therapeutic planning requires planners see themselves as community caregivers. Institutions can set that direction through their mandate and other guiding documents.

Before a planning institution can become therapeutic it must address its role in planning's dark side. A review of the institution's past actions allows the institution to reflect on how their policies, plans and techniques have contributed to colonialism, community trauma and conflict. Building a renewed planner-public relationship means mitigating activities and approaches that create harm. This process also allows planners within the institution to practice reflective practice and mindfulness which build into therapeutic communication. Some elements of planning's dark side may be too challenging for an institution to entangle in the short term. In those conditions, a review process signals to the community that the planning institution acknowledges the role history and emotions play in the present. Such a process of recognition is a critical first step in creating the space to move forward. Sandercock \& Atilli say that therapeutic planning "begins with a recognition that the past is often very present in planning conflicts, that past injustices shape what is possible in the present and often prevent constructive solutions from emerging, until and unless there is a process of recognition and working through these historic wounds and memories" (2014).

Some other recommended documents include public engagement and communications strategies that focus on how institutions frame their relationship to the public through therapeutic 
communication techniques. Effective therapeutic communication requires institutions build public engagement models and staff training regimes to support a holistic understanding of theory and practice. Therapeutic planning theorists (Erfan, 2017; Sandercock \& Atilli, 2014) recommend having specialized therapeutic practitioners due to the degree of specialized communication knowledge required. Institutions may want to follow this direction, but if all of the planning profession is to become healing and transformative, these specialists should be used as broadly as possible.

If institutions are considering embracing the therapeutic planning model, they can turn to Waterfront Toronto as an example. Waterfront Toronto is in the process of implementing a model of compassionate planning which shares many similarities with therapeutic planning. They are currently developing strategic documents and training for their community engagement division based on compassionate principles. As it is still early in the development of their model, it is too early to comment on the successes and challenges involved in institutional implementation. Waterfront Toronto is a perfect candidate for further research to understand what therapeutic planning could look like in a major planning institution. Other planning institutions should follow their lead and implement therapeutic planning into their practice.

This paper recommends that planning institutions:

1. Update company/division mandate to include providing community care and fostering community healing and transformation.

2. Conduct a review of how the institution's past planning activities have contributed to colonialism, community trauma and conflict.

3. Develop a public engagement and communications strategy that prioritizes community care and includes therapeutic communication techniques.

4. Provide training for employees in theory of care, mindfulness, reflective practice, and therapeutic communication techniques.

\subsection{In public engagement processes}

Moving down a level to the experience of individual planners we will now explore how therapeutic planning looks like in a specific public engagement process. We will use the public 
meeting as a stand in because of its prominence as a public engagement tool, but these recommendations can be applied in any public engagement or public consultation process.

To begin, before an engagement activity even takes place it is important to understand the socio-emotional space of the community that is being engaged. Not all planning contexts will have the level of community conflict and trauma as planning with indigenous communities because colonialism is a rather embedded and complex harm. Some communities will bring that level of emotional complexity to the situation in which case the more specialized therapeutic communication techniques like deep democracy should be applied. However, in most contexts a simpler intervention may be required. One of the strengths of therapeutic planning is that it equips planners to respond to a wide range of communities.

Public meetings carry a legacy of trauma for both communities and the planners that facilitate them. A preliminary reflective process can help planners unpack the dark side of public meetings and how they can create space for transformation. Special attention should be paid to the potential for indigenous communities and other marginalized groups to be further harmed by this process. When preparing the format of the public meeting planners should ask themselves how they can create space for that history and for the emotional experience of participants. Designing an engagement activity like Sarkissian's speak out (Sandercock, 2003) allows the emotional experience of participants to be held and creates the opportunity for transformation and healing. Even with the inclusion of such an engagement activity, the public meeting is still a planning process where the goal is to move through the emotional experience of participants towards collective decision making. Recognizing the emotional experience of participants allows trauma and conflict to fuel that decision making rather than inhibit it.

Therapeutic planning requires an engagement team with the facilitative skills to hold conflict and trauma. Depending on the context, you may need to bring in therapeutic practitioners with 
more specialized skills. However, for most situations planners should be trained to recognize the role history, trauma and conflict play in the decision-making process and create space for them to be worked through. Throughout the public meeting it would be advisable to incorporate elements of reflective practice and mindfulness to help participants be present to their emotional experience, manage planner bias and address other problems as they arise. To continue with the iterative learning required for such care a final review of the evening should be undertaken addressing participant experience.

This paper recommends that planner's conducting public engagement processes:

1. Conduct a preliminary scan of the community to identify any community traumas or conflicts that could influence participant experience of the process.

2. Conduct a review of how the proposed process could contribute/mitigate the experience of trauma for indigenous communities and any other groups that have been harmed by past planning actions.

3. Design an engagement process that treats emotions and conflict as valid expressions and creates space for them to be held in a respectful manner.

4. Select/train an engagement team with skills in therapeutic communication.

5. Incorporate elements of reflective practice and mindfulness throughout the process.

This chapter has provided planners with some concrete recommendations to begin implementing the principles and techniques of therapeutic planning in their practice. While the responsibility for a more therapeutic approach to planning is great, planners need not fear. As this section has shown, there is ample opportunity to begin moving forward in planning education, professional bodies, planning firms/departments and in everyday public engagement activities. The recommendations above are to be used as a launch pad; inspiring planners to examine their practice for the possibility of care. The transformative power of therapeutic planning begins when planners are able to transform their self-perception of themselves into community caregivers. Implementing even one of these recommendations creates space for planners to begin to embrace the therapeutic imagination. 


\section{CONCLUSION}

This paper sought to make the case for a therapeutic transformation across planning. Through an examination of if and how planners might begin to integrate therapeutic planning into their practice, this paper found ample opportunity for therapeutic planning throughout the profession. Planning has always had the foundation of a caring profession as it is fundamentally about the public-planner relationship and is committed to the public interest. When one examines planning history through the lens of care several elements of care emerge. The planner has been an expert for the public on their interests; has been a negotiator between the ideals of the public interest and the constraints of heterogenous society; has been a facilitator of a public discourse for all members of the community; and has been an advocate for the marginalized of society against the systems of power that divide them. Therapeutic planning opens up a new pathway for the profession as a community caregiver. This pathway brings the concept of care back into the foreground of planning rationale and awakens an imagination for healing and transformation.

In the wake of the growing calls for reconciliation, planning can no longer see therapeutic planning as solely a specialized planning tool. Conflict and trauma are fundamental parts of the planning process and carry their histories into every planning decision. The therapeutic communication techniques that come with therapeutic planning provide a diverse and flexible toolkit to help planners transform communities. This transformation becomes all the more important as planners can no longer ignore the profession's dark side. There is a moral obligation for planners to do better when it comes to the emotional experiences and lived stories of the public.

From this paper, there is fertile ground for further research. On the theoretical side, more thought needs to go into what exactly a theory of care for planning should look like. The caring professions have already spent decades parsing out the dynamics of care and it is time that planning theorists bring the richness of that discourse into the planning context. For planning to move into a 
community caregiver role, questions are raised around the professions shifting boundaries. How does the therapeutic planner align next to community psychologists, sociologists and social workers? How can planning better communicate with these other professions? Moving to the applied side of therapeutic planning, more research needs to be done into the best methods of educating planners, both in planning schools and in professional practice. For example, how can therapeutic communication skills be made as accessible as possible? Seeing as therapeutic planning has seen little application outside of the indigenous planning context, more study needs to be done on the effects of a broader application of therapeutic planning. Research trials and case studies across a broad range of planning contexts will be valuable assets in flushing out the true potential of therapeutic planning moving forward.

This paper made the case for a broader application of therapeutic planning. It has also provided a rooted set of recommendations for planners to move forward. There is room within the field's public engagement strategies to begin equipping planners and the public with the concepts and tools of therapeutic planning. However, for these reforms to truly set in they must be supported by planning institutions like planning schools, professional bodies, planning firms and municipal planning departments. The challenge of therapeutic planning is that it calls for a reimagination of the very identity of planning. Whether or not planners can truly become a caring profession and adopt a community caregiver role depends on further research and visionary initiatives like Waterfront Toronto's compassionate planning. With the legacies of colonization, trauma and conflict, it is difficult for planners to ignore the transformative potential of therapeutic planner. 


\section{WORKS CITED}

Agyeman, J., \& Erickson, J. S. (2012). Culture, Recognition, and the Negotiation of Difference. Journal of Planning Education and Research,32(3), 358-366.

Allmendinger P \& Gunder M (2005). Applying Lacanian insight and a dash of Derridean deconstruction to planning's dark side. Planning Theory 4(1): 87-112

Amborski, D. (2018, March 16).

Andersen, J. (2007). "Empowermentperspektivet i planlægning." [The Perspective of Empowerment in Planning]. In Planlagning i teori og praksis - et tvarfagligt perspektiv [Planning in Theory and Praxis - An Interdisciplinary Perspective], edited by A. Jensen, J. Andersen, O. E. Hansen, and K. Aa. Nielsen (red.), 46-62. Copenhagen: Roskilde University Press.

Arnstein, S. R. (1969). A ladder of citizen participation. Journal of the American Institute of Planners, 35(4), 216-224.

Banfield, E. (1955). "Note on a Conceptual Scheme," in Politics, Planning and the Public Interest, by Edward C. Banfield and Martin Meyerson. Free Press.

Baum, H. (2010). Planning and the problem of evil. Planning Theory,10(2), 103-123. doi:10.1177/1473095210372268

Baum, H. (2015). Planning with half a mind: Why planners resist emotion. Planning Theory \& Practice, 16(4), 498-516.

Bollens, S. A. (2006). Urban planning and peace building. Progress in Planning, 66(2), 67-139.

Brook, C. (2017, December 1). Land and Truth/Land and Reconciliation. OPPI. http://ontarioplanners.ca/Blog/Planning-Exchange/December-2017/Land-and-TruthLand-and-Reconciliation

Bush, R. A., \& Folger, J. P. (1994). Promise of mediation: The transformative approach to conflict. San Francisco: Jossey Bass.

City of Toronto. (2016, October 27). Request for a Report on the Implementation of a One-Year Moratorium on new Tall Building Residential Development in the Downtown Core. https://www.toronto.ca/legdocs/mmis/2016/te/bgrd/backgroundfile-97790.pdf

Davidoff, P. (1965). Advocacy and Pluralism in Planning. Journal of the American Institute of Planners. 31 :331-338

Derrida J (2001). On Cosmopolitanism and Forgiveness, London: Routledge.

Digeser P (2001) Political Forgiveness. Ithaca, NY: Cornell University Press.

Doane, G. H., \& Brown, H. (2010). Recontextualizing Learning in Nursing Education: Taking an Ontological Turn. Journal of Nursing Education,50(1), 21-26. doi:10.3928/01484834-2010113001

Doane, G. H., \& Varcoe, C. (2007). Relational Practice and Nursing Obligations. Advances in Nursing Science,30(3), 192-205

Donald, J. (1999) Imagining the Modern City. London: The Athlone Press.

Dorries, H. (2012). “Rejecting the 'False Choice': Foregrounding Indigenous Sovereignty in Planning Theory and Practice." Unpublished PhD dissertation, Department of Geography, University of Toronto.

Elling, B. (2017). Communicative planning as counter-power. International Planning Studies,22(3), 226241. doi: $10.1080 / 13563475.2016 .1253458$

Erfan, A. (2017). Confronting collective traumas: An exploration of therapeutic planning. Planning Theory \& Practice, 18(1), 34-50.

Etzioni, A. (1967). Mixed Scanning: A Third Approach to Decision Making. Public Administration Review. 27:385-392.

Faludi, A. (1973). Planning Theory. Pergamon 
Fischer, F. (2000). Citizens, Experts and the Environment - The Politics of Local Knowledge. Durham, NC: Duke University Press.

Forester, J. (1999). The deliberative practitioner: Encouraging participatory planning processes. MIT Press.

Forester J. (2009). Dealing with Differences. Oxford: Oxford University Press.

Fried, M. (1966) Grieving for a Lost Home: Psychology of Relocation. In: Wilson, J. (eds.) Urban renewal: the record and the controversy. Cambridge, MA: M.I.T. Press.

Friedmann, J. (1987). Planning in the Public Domain: From Knowledge to Action. Princeton, NJ: Princeton University Press.

Fullilove, M. (2004). Root shock: How tearing up city neighborboods burt America, and what we can do about it. New York, NY: Ballantine Books.

Government of Ontario. (2014). Provincial Policy Statement.

Gunder M \& Hillier J. (2007) Planning as urban therapeutic. Environment and Planning- Part A 39(2): 467-486

Healey, P. (1997). Collaborative planning: Shaping places in fragmented societies. UBC Press

Hibbard, M., and M. Lane. (2004). "By the Seat of Your Pants: Indigenous Action and State Response." Planning Theory and Practice 5 (1): 97-109.

Hillier J (2002) Off the slippery ice and onto rough ground: Direct action and agonism in democratic planning practice. In: Allmendinger P \& Tewdr-Jones M (Eds) Planning Futures: New Directions in Planning Theory. London: Athlone Press, pp. 110-135.

Hillier, J. (2010). Introduction to Part Three. In the Ashgate Research Companion to Planning Theory, edited by J. Hiller and P. Healey, 367-398. Surrey: Ashgate.

Hoch, C. (2006). Emotions and planning. Planning Theory \& Practice, 7(4), 367-382.

INAC. (2018). Fact Sheet - Urban Aboriginal population in Canada. http://www.aadncaandc.gc.ca/eng/1100100014298/1100100014302

Innes, J. E. (1998). Information in Communicative Planning. Journal of the American Planning Association 64 (1): 52-63.

Innes, J. E., and D. E. Booher. (2000). Planning Institutions in the Network Society: Theory for Collaboratory Planning. In the Revival of Strategic Spatial Planning, edited by W. Salet and A. Faludi, 175-189. Amsterdam: Royal Netherlands Academy of Arts and Science.

Jackson, S. (1998). "Geographies of Co-existence: Native Title, Cultural Difference and the Decolonization of Planning in North Australia." Unpublished PhD dissertation, School of Earth Sciences, Macquarie University, Sydney.

Jojola, T. (1998). "Indigenous Planning: Clans, Intertribal Confederations and the History of the AllIndian Pueblo Council." In Making the Invisible Visible: A Multicultural History of Planning, edited by L. Sandercock. Berkeley: University of California Press.

Jojola, T. (2008). Indigenous planning - An emerging context. Canadian Journal of Urban Research, suppl. Canadian Policy and Planning, 17, 37-47.

LeBaron, M. (2002). Bridging Troubled Waters. San Francisco: Jossey Bass.

Lindblom, C. (1959). The Science of Muddling Through, Public Administration Review. 19:79-88

Nightingale, F. (1989). Notes on Nursing: What it is, and What it is not. Edited by D. Appleton and Company. New York

Manzo, L., Kleit, R., \& Couch, D. (2008). "Moving three times is like having your house on fire once": The experience of place and impending displacement among public housing residents. Urban Studies, 45(9), 1855-1878.

Marris, P. (1974). Loss and change. London: Routledge \& Kegan Paul.

Matunga, H. (2013). Theorizing indigenous planning. In R. Walker, T. Jojola, \& D. Natcher (Eds.), Reclaiming indigenous planning (pp. 3-32). Montreal and Kingston: McGill-Queen's Univ. Press. 
McCormack, B. (2003). A Conceptual Framework for Person-Centred Practice with Older

People. International Journal of Nursing Practice,9(3), 202-209.

OPPI. (2018). Professional Code of Practice http://ontarioplanners.ca/KnowledgeCentre/Professional-Code-of-Practice

Pagliaro, J. (2016, February 17). OMB Reform: Onward and upward. Toronto Star. http://projects.thestar.com/ontario-municipal-board-reform/onward-upward/

Pløger J (2004) Strife: Urban Planning and agonism. Planning Theory 3: 71-92.

Porter, L. (2010). Unlearning the Colonial Cultures of Planning. Aldershot: Ashgate.

Posner EA \& Vermeule A (2004) Transitional Justice as ordinary justice. Harvard Law Review 117(3): 761-825.

Sandercock L. (2003). Cosmopolis 2: Mongrel cities of the $21^{\text {st }}$ century. London: Continuum.

Sandercock, L., \& Attili, G. (2014). Changing the Lens. Journal of Planning Education and Research,34(1), 19-29.

Schweitzer, L. (2016). Restorative planning ethics: The therapeutic imagination and planning in public institutions. Planning Theory, 15(2), 130-144.

Schwind, J. K., Beanlands, H., Lapum, J., Romaniuk, D., Fredericks, S., Legrow, K., Crosby, J. (2014). Fostering Person-Centered Care Among Nursing Students: Creative Pedagogical Approaches to Developing Personal Knowing. Journal of Nursing Education,53(6), 343-347.

Schwind, J. K., Lindsay, G. M., Coffey, S., Morrison, D., \& Mildon, B. (2014). Opening the blackbox of person-centred care: An arts-informed narrative inquiry into mental health education and practice. Nurse Education Today,34(8), 1167-1171.

Schön, D. A. (1983). The reflective practitioner: How professionals think in action Basic Books.

Sennet, Richard (1990). The Conscience of the Eye. New York: Norton.

Truth and Reconciliation Commission of Canada (2015). Calls to Action. http://www.trc.ca/websites/trcinstitution/File/2015/Findings/Calls_to_Action_English2.p df

Walker, R., T. Jojola, and D. Natcher. (eds.). (2013). Reclaiming Indigenous Planning. Montreal: McGillQueens University Press.

Yiftachel O (1998) Planning and social control: Exploring the dark side. Journal of Planning Literature 12(4): 95-406

Young, M. \& P. Willmott (1957). Family and Kinship in East London. London: Routledge Kegan Paul. Young IM (2011) Responsibility for Justice. Oxford: Oxford University Press. 